\title{
Comments on the Joint Proposed Rulemaking to Establish Light- Duty Vehicle Greenhouse Gas Emission Standards and Corporate Average Fuel Economy Standards Docket No. NHTSA-2009-0059 and Docket No. EPA-HQ-OAR-2009-0472
}

\author{
Tom Wenzel, Lawrence Berkeley National Laboratory
}

October 27, 2009

\author{
Presented by \\ Tom Wenzel \\ Energy Analysis Department \\ Environmental Energy Technologies Division \\ Lawrence Berkeley National Laboratory \\ Berkeley, CA 94720
}

October 2009

This work was supported by the Assistant Secretary for Energy Efficiency and Renewable Energy, Director of Strategic Planning and Analysis, of the U.S. Department of Energy under Contract No. DE-AC02-05CH11231. 


\section{DISCLAIMER}

This document was prepared as an account of work sponsored by the United States Government. While this document is believed to contain correct information, neither the United States Government nor any agency thereof, nor The Regents of the University of California, nor any of their employees, makes any warranty, express or implied, or assumes any legal responsibility for the accuracy, completeness, or usefulness of any information, apparatus, product, or process disclosed, or represents that its use would not infringe privately owned rights. Reference herein to any specific commercial product, process, or service by its trade name, trademark, manufacturer, or otherwise, does not necessarily constitute or imply its endorsement, recommendation, or favoring by the United States Government or any agency thereof, or The Regents of the University of California. The views and opinions of authors expressed herein do not necessarily state or reflect those of the United States Government or any agency thereof, or The Regents of the University of California.

Ernest Orlando Lawrence Berkeley National Laboratory is an equal opportunity employer. 


\title{
Comments on the Joint Proposed Rulemaking to Establish Light-Duty Vehicle Greenhouse Gas Emission Standards and Corporate Average Fuel Economy Standards Docket No. NHTSA-2009-0059 and Docket No. EPA-HQ-OAR-2009-0472
}

\author{
Tom Wenzel, Lawrence Berkeley National Laboratory \\ October 27, 2009
}

I appreciate the opportunity to provide comments on the joint rulemaking to establish greenhouse gas emission and fuel economy standards for light-duty vehicles. My comments are directed at the choice of vehicle footprint as the attribute by which to vary fuel economy and greenhouse gas emission standards, in the interest of protecting vehicle occupants from death or serious injury. I have made several of these points before when commenting on previous NHTSA rulemakings regarding CAFE standards and safety. The comments today are mine alone, and do not necessarily represent the views of the US Department of Energy, Lawrence Berkeley National Laboratory, or the University of California.

My comments can be summarized as follows:

- My updated analysis of casualty risk finds that, after accounting for drivers and crash location, there is a wide range in casualty risk for vehicles with the same weight or footprint. This suggests that reducing vehicle weight or footprint will not necessarily result in increased fatalities or serious injuries.

- Indeed, the recent safety record of crossover SUVs indicates that weight reduction in this class of vehicles resulted in a reduction in fatality risks.

- Computer crash simulations can pinpoint the effect of specific design changes on vehicle safety; these analyses are preferable to regression analyses, which rely on historical vehicle designs, and cannot fully isolate the effect of specific design changes, such as weight reduction, on crash outcomes.

- There is evidence that automakers planned to build more large light trucks in response to the footprint-based light truck CAFE standards. Such an increase in the number of large light trucks on the road may decrease, rather than increase, overall safety.

\section{Introduction}

Pinpointing the causes of a vehicle crash, and any fatalities or serious injuries that occur in crashes, is a very difficult task. Many variables can contribute to one vehicle model having a higher risk on-road risk than another model; these variables can be grouped into three general categories, driver characteristics and behavior, vehicle attributes and condition, and crash location and environment.

The 2003 NHTSA study (Kahane, 2003) did a thorough job accounting for many of the variables that may affect injury and fatality outcomes in crashes. However, even this comprehensive analysis did not account for all of these variables; indeed, it may not be possible to fully account for all of the important variables that determine crash outcomes. I have critiqued this analysis in comments submitted for previous NHTSA rulemakings (Wenzel and Ross, 2004a; Wenzel and Ross, 2004b; Wenzel and Ross, 2005; Wenzel and Ross, 2008). 


\section{Casualty risks}

In a recent analysis for the Department of Energy (Wenzel, 2009), I analyzed data on driver casualty risks for model year 2000 to 2004 vehicles, using all police-reported crashes from five states that report the vehicle identification number. The VIN is necessary to accurately identify vehicle year, type, make and model. I used the total number of vehicles involved in a crash, including those involved in property-damage only crashes, as the measure of exposure to casualty risk. The total number of crash-involved vehicles can act as a proxy of the number of miles a given vehicle type, or model, is driven per year, and is a preferable unit of exposure than merely the number of registered vehicles. Because there are relatively few fatalities in the five states, I calculated casualty risk, which is the sum of fatalities and serious or incapacitating injuries. Vehicle weight, wheelbase, track width, and sales are from EPA compliance data provided me by DOE. For models with a range of footprints and curb weights, sales-weighted values for each model were calculated by weighting the values for the different versions by the total sales of each version. Because the footprint and weight data come from CAFE compliance records, data are not available for light trucks larger than 8,500 lbs gross vehicle weight that are exempt from CAFE standards (Ford and GMC 3/4-ton pickups, and all 1-ton pickups and vans). Therefore, this analysis excludes the largest pickups and vans.

Because both the numerator (crash casualties) and denominator (total number of crashes) of the risk estimates come from the same dataset, I can exclude certain cases from the analysis in order to account for various effects that may bias the estimated casualty risks by vehicle type and model. For example, young males, because of their inexperience and aggressive driving, tend to have higher casualty risks than other drivers; elderly drivers tend to have higher casualty risks because they are less able to sustain crash forces in a serious crash. I exclude both young males and elderly drivers from my analysis to limit the effect that differences in drivers among vehicle types have on estimated casualty risks. Similarly, casualty risks tend to be higher in very rural counties, and lower in very urban counties, because of a variety of factors. I also exclude crashes in very rural and very urban counties to account for these factors.

My analysis indicates that, on average, casualty risk to drivers does tend to decrease as vehicle weight (Figure 1) or footprint (Figure 2) increases. The relationship between casualty risk and weight is stronger for cars than for light trucks (minivans, SUVs, and pickups); however, there still is a wide range in casualty risk for individual vehicle models of the same type, weight, and footprint. The worst car models can have a casualty risk $50 \%$ higher to two times higher than the safest car models, even after accounting for differences in the number of miles driven, driver age and gender, and crash location by vehicle model. 
Figure 1. Relationship between casualty risk to drivers and vehicle curb weight, by vehicle type and model (casualty risk is calculated excluding crashes involving young male or elderly drivers, and crashes in very rural or very urban counties)

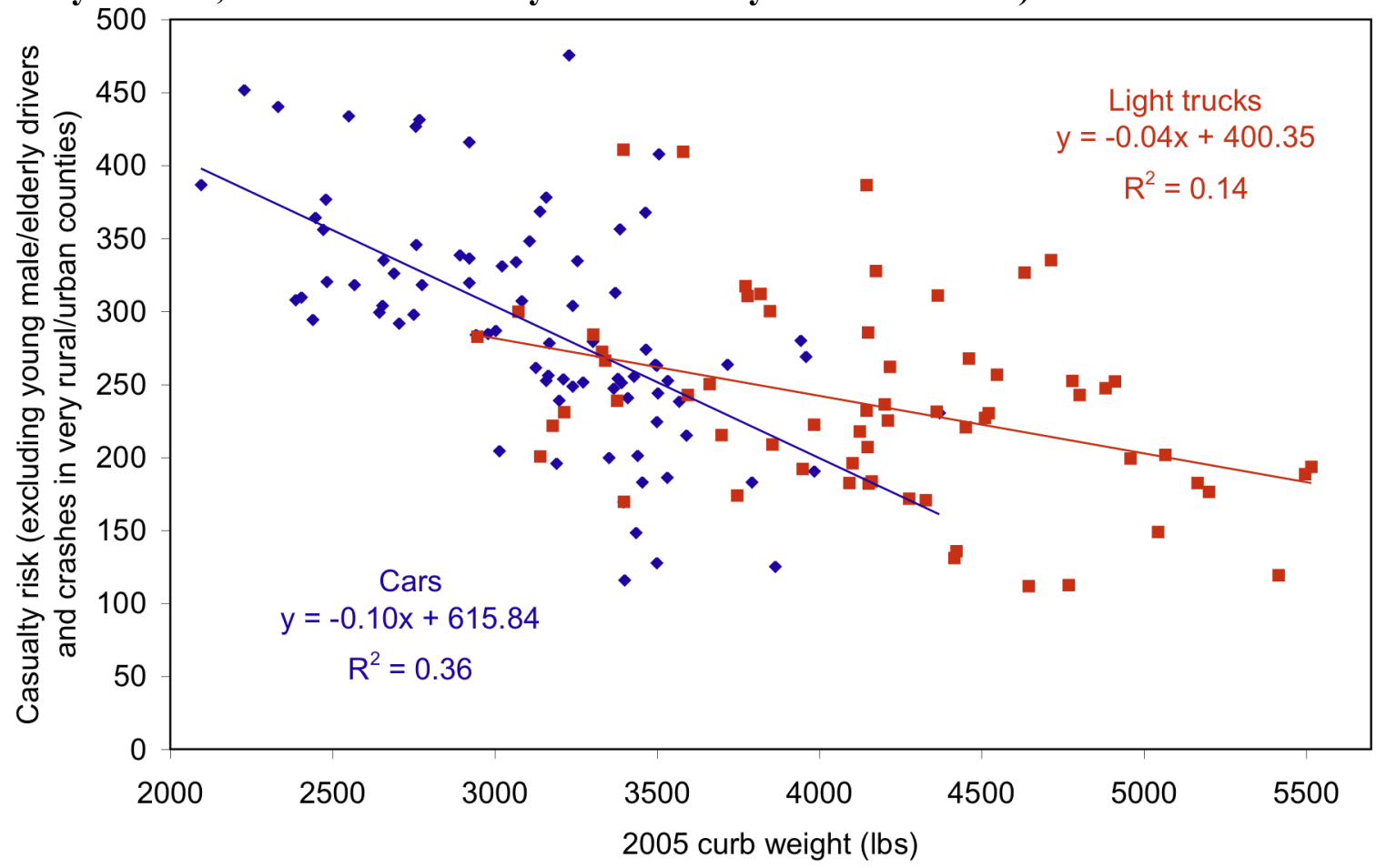

Figure 2. Relationship between casualty risk to drivers and vehicle footprint, by vehicle type and model (casualty risk is calculated excluding crashes involving young male or elderly drivers, and crashes in very rural or very urban counties)

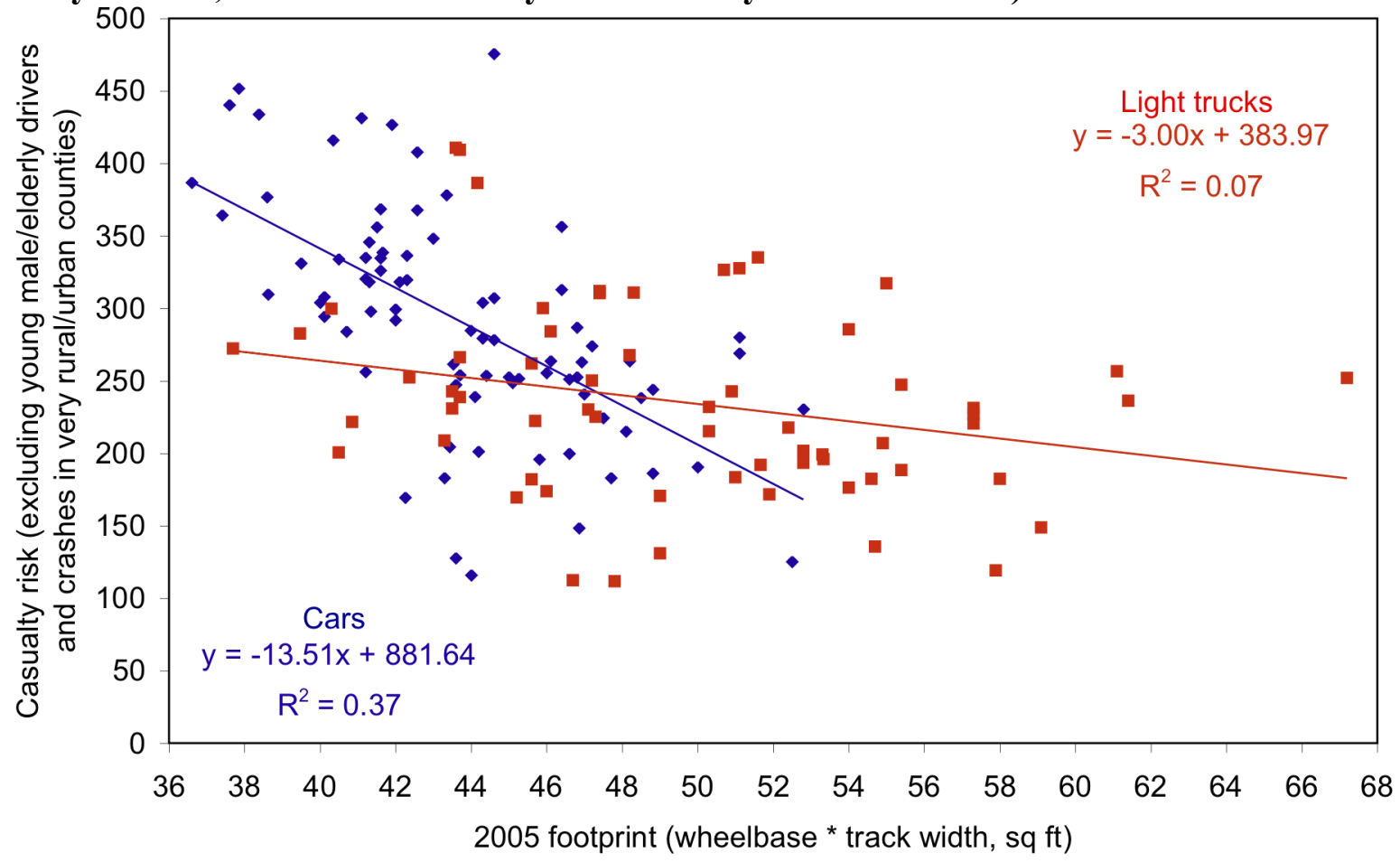


One would think that wheelbase (or vehicle length) would be protective in frontal crashes, while track width (or vehicle width) should protect in side impact crashes. However, I find that the relationship is not particularly strong between vehicle wheelbase and casualty risk in frontal crashes, or track width and casualty risk in driver-side crashes.

There also is a wide range in risk imposed on drivers of other vehicles, for vehicles with the same weight (Figure 3) or footprint (Figure 4). However, I find that the risks imposed by light trucks on drivers in other vehicles tend to increase as light truck weight or footprint increases.

Figure 3. Relationship between casualty risk to drivers of other vehicles and vehicle curb weight, by vehicle type and model (casualty risk is calculated excluding crashes involving young male or elderly drivers, and crashes in very rural or very urban counties)

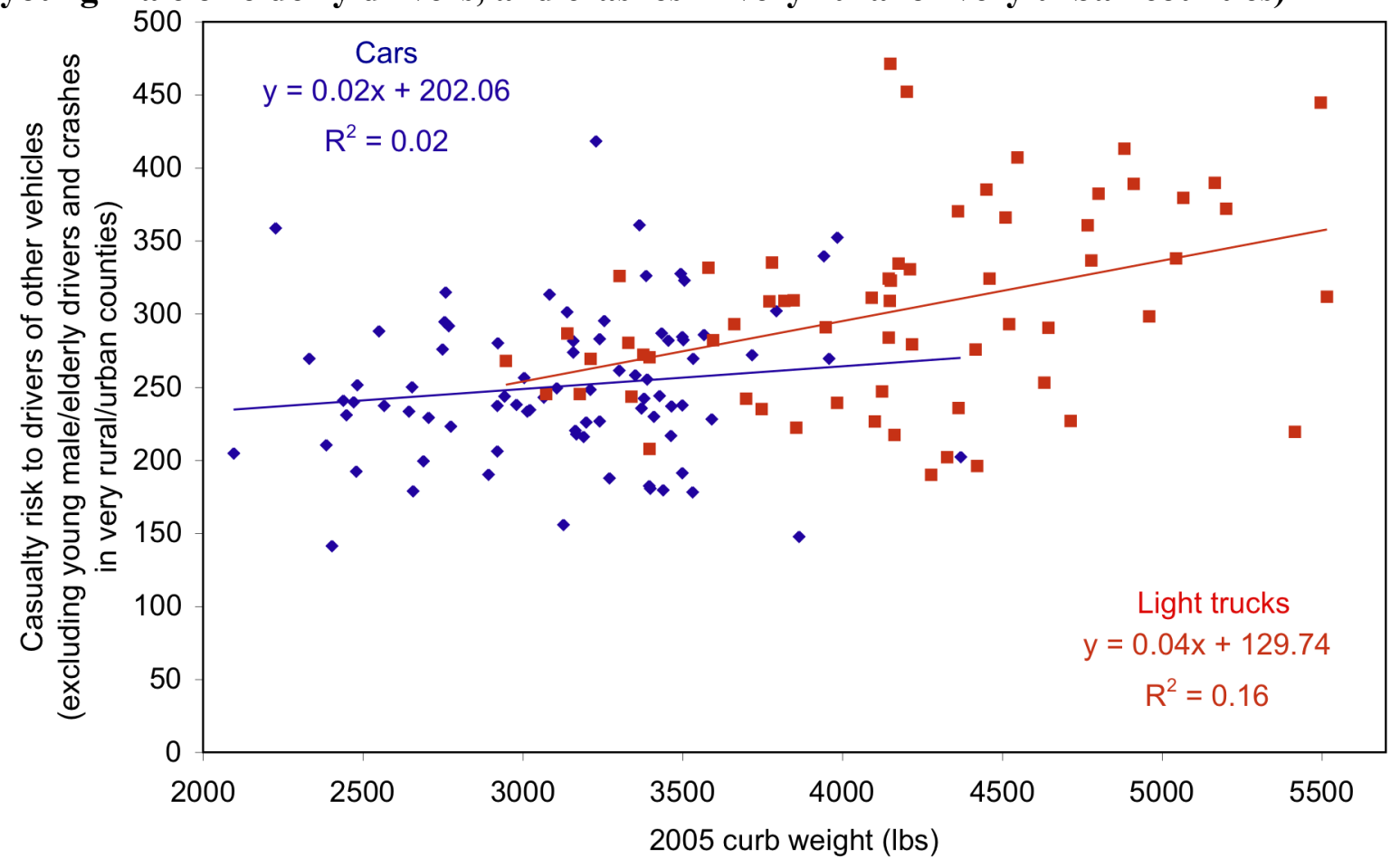


Figure 4. Relationship between casualty risk to drivers of other vehicles and vehicle footprint, by vehicle type and model (casualty risk is calculated excluding crashes involving young male or elderly drivers, and crashes in very rural or very urban counties)

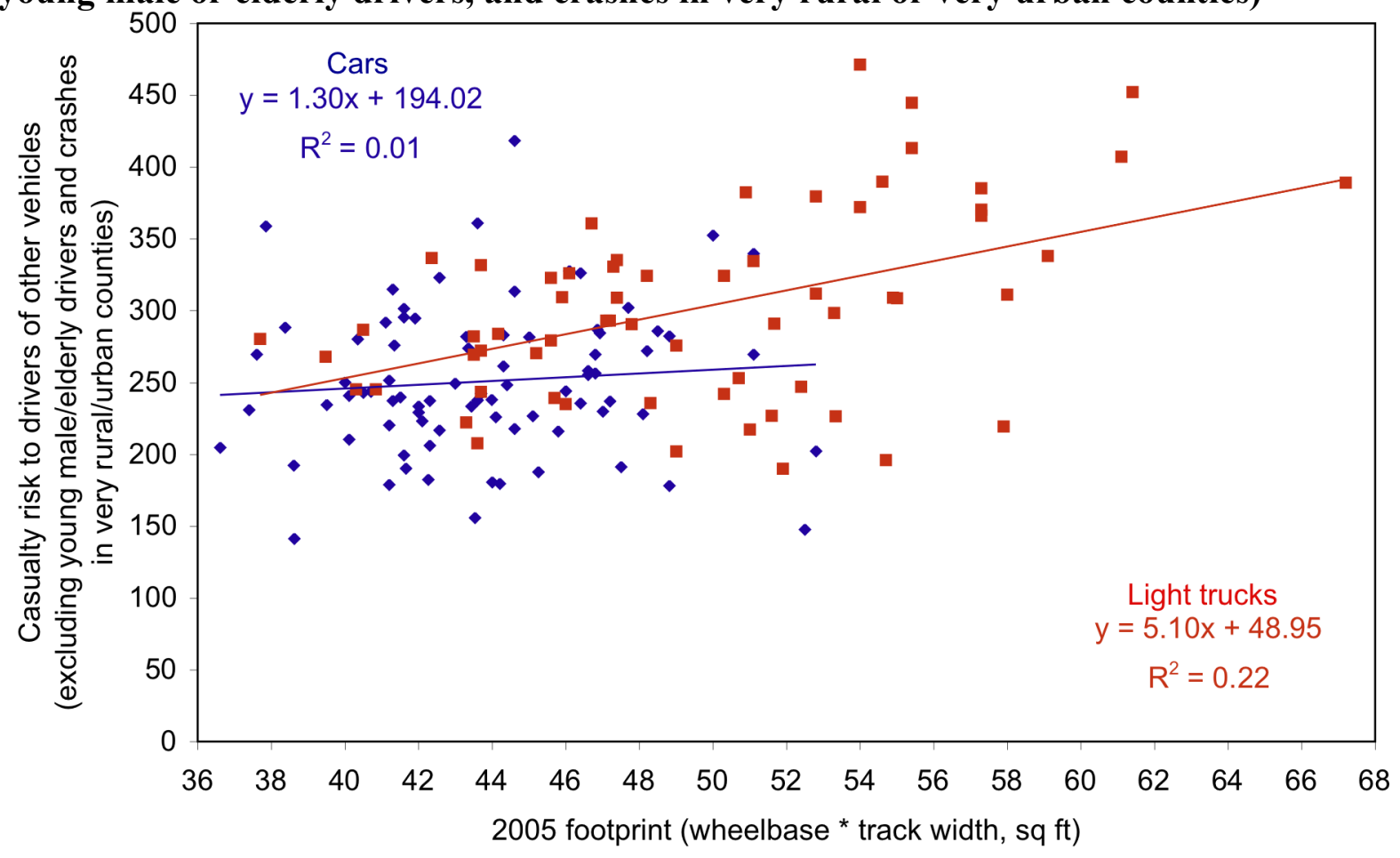

The wide range in risk among vehicle models, both to own drivers and to drivers of other vehicles, indicates that an across-the-board reduction in vehicle weight or footprint would not automatically lead to additional fatalities. There are examples of vehicles on the road today that have relatively low weight or footprint, and lower than average risk. A regression model like NHTSA's only considers the average trend in the relationship between vehicle weight or size and risk, and ignores those vehicles that do not follow that trend.

To illustrate why the NHTSA regression approach does not, and perhaps cannot, accurately reflect how automakers will respond to the proposed standards in their future designs, I offer the following example, taken from Figure 1 above and shown in more detail in Figure 5.

The Dodge Neon has an average weight of $2920 \mathrm{lbs}$, and, for a middle-aged driver in a suburban area, a casualty risk of 320 per 10,000 vehicles involved in a crash. In effect, a regression analysis like Kahane's assumes that if $170 \mathrm{lbs}$ of weight were taken out of the Neon, its risk would increase to 340 , by moving up the regression line for all car models. This level of risk is comparable to that of a Lancer, which has an average weight of $2760 \mathrm{lbs}$ and has a casualty risk of 346 (in blue in Figure 5). The Protege and Sephia (in red) also weigh about 2750 lbs; however, their risk ranges from 298 for the Protégé (which is 15\% less than that of the Lancer) to 427 for the Sephia (which is $25 \%$ more than that of the Lancer). The NHTSA regression assumes that, in removing $170 \mathrm{lbs}$ from the Neon, Chrysler engineers will necessarily convert it into the equivalent of a Lancer. But will the weight reduction actually result in the equivalent of a Protege, or perhaps a Sephia? Indeed, Chrysler engineers may be capable of converting the 
Neon into the equivalent of a Matrix, Civic, or Corolla (in green), all of which have the same risk as the Neon but weigh $5 \%, 10 \%$, and $15 \%$ less, respectively.

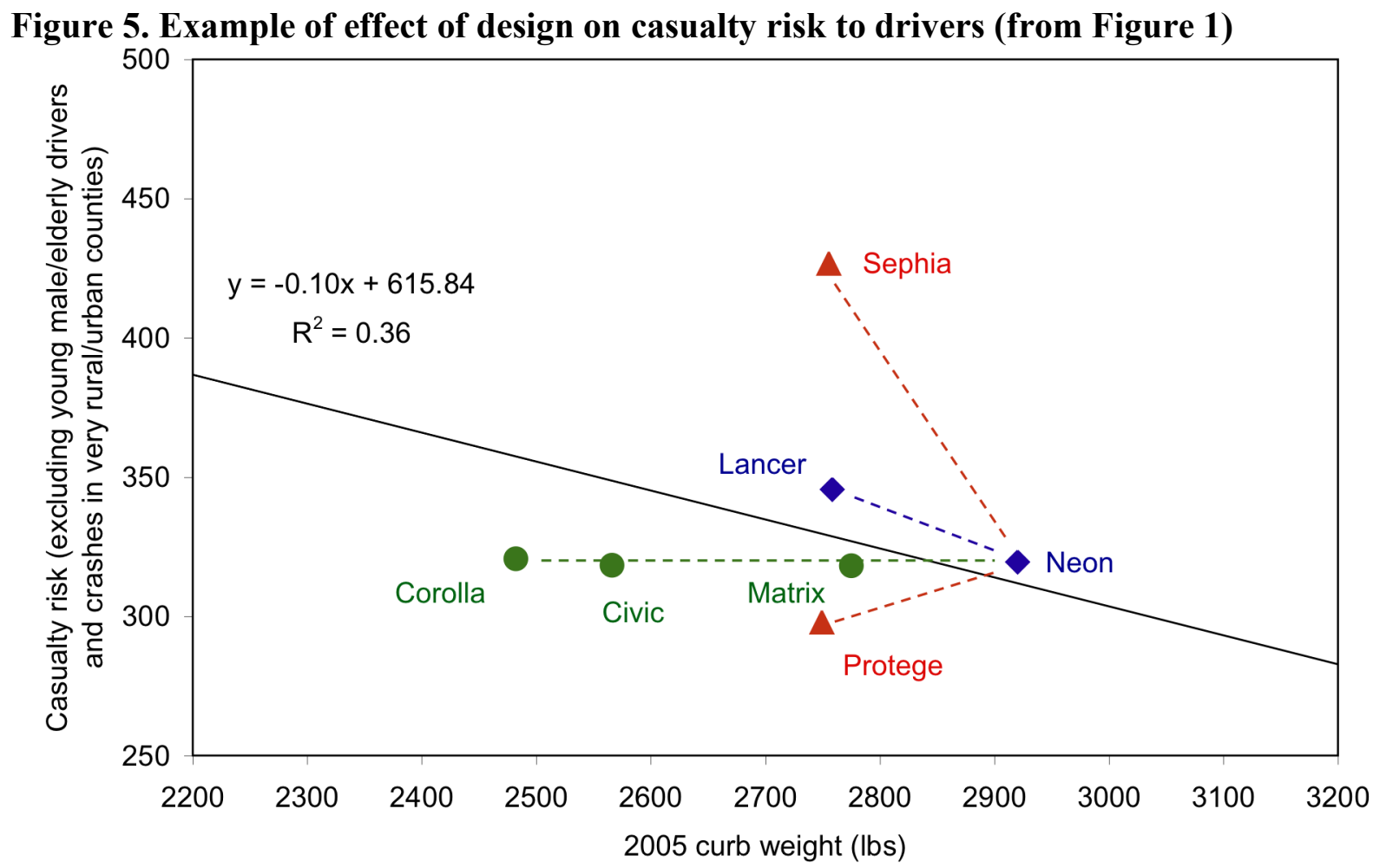

The bottom line is that there is no reason to believe, given today's competitive and safety conscious market, that, given adequate lead time, automakers would make their vehicles less safe. The industry can, and indeed already does, produce vehicles that have relatively low mass and that are at least, if not more, safe than the average vehicle.

\section{Crossover SUVs}

In its Regulatory Impact Analysis, NHTSA estimates that, under a worst case scenario, reducing the weight of vehicles will result in additional annual fatalities. This estimate is based on the results of the 2003 NHTSA regression analyses. NHTSA does not provide a "best case" scenario, despite the finding of the 2005 DRI regression analyses (Van Auken and Zellner, 2005) which indicate that fatalities would be reduced if vehicle weight were reduced while holding track width constant. NHTSA states that "Until there is a more credible analysis than the 2005 DRI study that demonstrates that mass does not matter for safety, NHTSA concludes it should be guided by the decades' worth of studies suggesting that mass is the most important of the related factors."

"NHTSA's analyses do not corroborate the 2005 DRI analysis that suggested mass could be reduced without safety harm and perhaps with safety benefit...it would seem the least harmful way to reduce mass would be from materials substitution, where one replaces a heavy material with a lighter one that delivers the same performance, or other designs that 
reduce mass while maintaining wheelbase and track width....We cannot analyze data on that yet, because those changes have not happened to any substantial number of vehicles...Until there is a more credible analysis than the 2005 DRI study that demonstrates that mass does not matter for safety, NHTSA concludes it should be guided by the decades' worth of studies suggesting that mass is the most important of the related factors." (NHTSA PRIA Section IX, p. 425)

Contrary to NHTSA's assertion, there is strong evidence that weight can be reduced while maintaining size and at least maintaining, if not increasing, occupant safety. In model year 1996, only $2 \%$ of SUV sales were car-based crossover SUVs; by 2005, half of SUVs sold were crossovers. Crossover SUVs are characterized as having unibody construction similar to cars, which eliminates the rigid longitudinal frame rails in truck-based SUVs and pickup trucks that are often deadly to occupants in other vehicles. In addition, crossover SUVs tend to have a lower center of gravity than truck-based SUVs, which makes them less likely to roll over.

Crossovers with the same footprint have about 10\% lower mass, and substantially lower risk, than truck-based SUVs (Table 1). The risks in Table 1 are national driver fatalities per million registered vehicles, for model year 2003 to 2007 vehicles. Compared to truck-based SUVs, compact crossovers have 36\% lower risk, and midsize crossovers have $49 \%$ lower risk, to their drivers. Small crossovers also impose 31\% lower risk on drivers of other vehicles than small truck-based SUVs, while midsize crossovers impose 37\% lower risk on others than comparable truck-based SUVs. I see similar results when I account for driver age and crash location, using casualty risks for 2000 to 2004 vehicles from the state crash data, as described above.

Table 1. Comparison of footprint, curb weight and fatality risk, for model year 2003 to 2007 SUVs and crossover SUVs

\begin{tabular}{|l|cc||cc|}
\hline Item & $\begin{array}{c}\text { Compact } \\
\text { SUV }\end{array}$ & $\begin{array}{c}\text { Midsize } \\
\text { SUV }\end{array}$ & $\begin{array}{c}\text { Compact } \\
\text { Crossover SUV }\end{array}$ & $\begin{array}{c}\text { Midsize } \\
\text { Crossover SUV }\end{array}$ \\
\hline Footprint (sq ft)* & 42 & 49 & 43 & 49 \\
Curb weight (lbs)* & 3672 & 4500 & $3359(-313)$ & $4081(-419)$ \\
Casualty risk to drivers & $69 \pm 9$ & $63 \pm 4$ & $44 \pm 4(-36 \%)$ & $32 \pm 3(-49 \%)$ \\
Casualty risk to others & $52 \pm 8$ & $59 \pm 4$ & $36 \pm 4(-31 \%)$ & $37 \pm 4(-37 \%)$ \\
\hline
\end{tabular}

* Sales-weighted averages for MY05 models

Because 1999 was the last year of data covered in the 2003 NHTSA analysis, and only 10\% of model year 1999 SUVs were crossovers, the 2003 analysis does not account for the rapid penetration of crossovers into the new vehicle market, and their effect on the relationship between vehicle weight, footprint, and risk. An updated regression analysis of data on model year 2000 and newer vehicles would likely find that reducing SUV mass, while maintaining size, would reduce casualty risk, similar to DRI's previous finding using fatality data.

Of course it is possible that factors other than weight reduction account for the lower risks in crossover SUVs; for example, unibody construction, lower bumpers, and less rigid fronts make crossovers more compatible with cars than truck-based SUVs. NHTSA's own research indicates that light truck bumper height and frontal stiffness are dangerous to car occupants, even after accounting for light truck weight; and lower height and center of gravity, stronger roofs, and 
perhaps early adoption of electronic stability controls may account for the lower rollover fatalities in crossover SUVs. NHTSA should acknowledge that other vehicle attributes may be as important, if not more important, than vehicle weight or footprint in terms of occupant safety.

\section{Computer crash simulation modeling}

These results regarding crossover SUVs are supported by a recent DRI study commissioned by the Aluminum Association (Kebschull et al., 2004). DRI used computer crash engineering models to simulate the effect that changing a SUV's mass or footprint would have on crash outcomes, without changing any other attributes of the SUV. DRI found that reducing SUV mass by $20 \%$ slightly increased the number of serious injuries to the SUV drivers, but cut in half the number of serious injuries to drivers of other vehicles. On balance, the computer simulation found a net $15 \%$ decrease in serious injuries in all vehicles. Similarly, increasing SUV wheelbase (by 4.5 inches) while maintaining its weight resulted in a $26 \%$ reduction in serious injuries in all vehicles.

These types of computer crash simulations are valuable because they allow the study of the independent effects of specific design changes, holding all other vehicle attributes constant. They are preferable to statistical regression models for two reasons: first, regression models frequently do not, and perhaps cannot, fully account for all the design differences between vehicle models, or their drivers, that contribute to their on-road safety record. Second, regression models are limited to the vehicle designs currently available on the market; they cannot accurately predict what effect any future large-scale changes in vehicle design, such as those induced by tough fuel economy and emission standards, would have on occupant safety.

\section{Two-door cars}

The 2003 NHTSA regression analysis excluded two-door cars because these vehicles tend to be driven aggressively, which makes the vehicles themselves appear to be more risky than four-door models of the same weight. The exclusion of a class of vehicles because of their drivers' behavior suggests that the NHTSA regression model does not fully account for driver characteristics and behavior for other vehicle types (such as the relatively safe drivers of minivans). Our analysis of model year 2000 to 2004 cars in the crash data from five states indicates that, in general, the 4-door version does tend to have a lower casualty risk than the 2door version of the same model; however, the risk is lower even after one accounts for driver age and gender and crash location, which suggests either that driver behavior does not account for the greater risk in 2-door vehicles, or that the difference in driver behavior is not fully captured by excluding young male and elderly drivers. In two models (Alero and Stratus), the risks in the 4-door version are consistently higher than those in the 2-door version.

In crashes involving 2000 to 2004 vehicles, only $25 \%$ of all 2-door cars are 8 models that only come in 2-door versions, and could be considered sports or sporty cars (Mustang, Eclipse, Celica, Tiburon, Camaro, Firebird, RSX, and Corvette). The remaining 75\% are mostly 2-door versions of 22 models that would not be considered sports cars (Civic, Cavalier, Sunfire, Accent, Accord, Focus, etc.). Removing 2-door cars from our analysis of casualty risk in five states increases the correlation between casualty risk and curb weight ( $\mathrm{R} 2$ improves from 0.36 to 0.50 ) 
and footprint (from 0.36 to 0.41 ), even after excluding young male drivers; nearly all of this improvement comes from removing the eight sports car models. In subsequent analyses NHTSA should include 2-door vehicles; a variable indicating whether the vehicles are sports cars can be included to account for any additional risk taken by drivers of these car models.

\section{Automaker response to proposed standards}

NHTSA based its recent CAFE standards on vehicle wheelbase and track width, in part to reduce the incentive for manufacturers to increase a vehicle's footprint in order for it to qualify for a lower CAFE target. Nonetheless, it appears that manufacturers planned to increase the footprint of their light trucks once NHTSA announced the footprint-based standard.

Figure 6 compares the manufacturer production plans submitted to NHTSA for the proposed (2005) and the final (2006) Reformed CAFE light truck rules. I recreated the data by visually extracting the distribution of sales by footprint from Figures 9 and 10 in the final Reformed CAFE light truck rule. Figure 6 indicates that after the first footprint-based standards were proposed, manufacturers planned to continue building larger light trucks. For instance, the planned production of the largest trucks (with a footprint greater than 65 square feet) doubled, from $8 \%$ to $16 \%$ of all planned light truck production. Undoubtedly some of this upsizing of light trucks is the result of the continued exemption of pickups between 8,500 and 10,000 lbs GVWR from CAFE; the Energy Independence and Security Act of 2007 (EISA) required that these pickups be addressed in a separate rulemaking. And auto manufacturers have likely revised these production plans in the face of their current financial situation, volatile gas prices, and the economic downturn. However, Figure 6 indicates that the announcement of the footprint-based standards did not necessarily discourage manufacturers from producing more light trucks with larger footprint. Because these large trucks are particularly dangerous to drivers of cars, the footprint-based standards may result in a net decrease in overall safety. 
Figure 6. Distribution of manufacturer planned MY2011 light truck production, by footprint bin

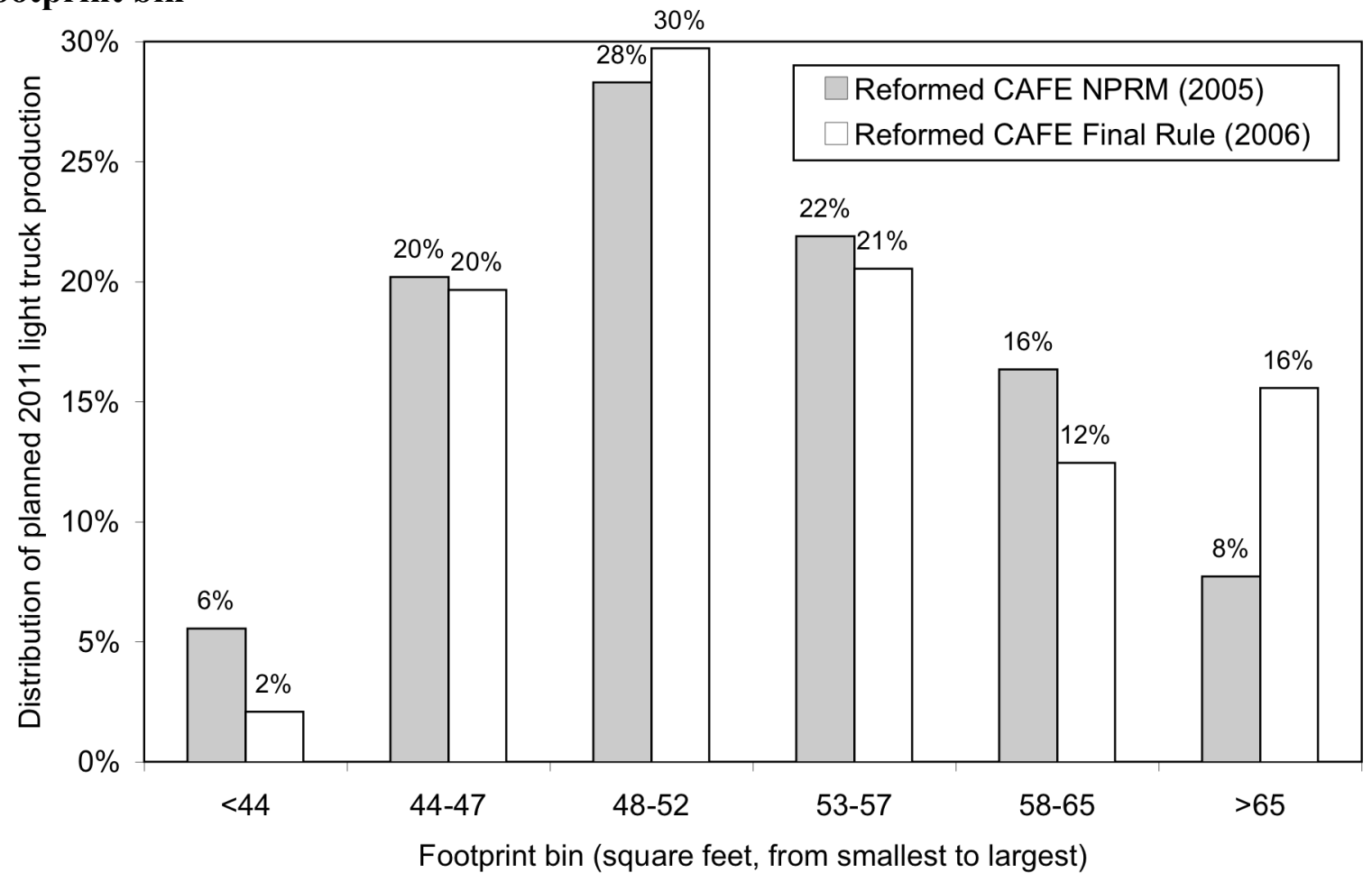

\section{Conclusions}

In conclusion, I have shown that reducing vehicle weight, or footprint, will not necessarily result in increased fatalities or serious injuries. Indeed, the recent safety record of crossover SUVs indicates that overall safety increased when the weight of these vehicles was reduced.

Statistical regression analyses are imperfect tools to predict the effect of changes in vehicle design on occupant safety; computer crash simulations can better pinpoint the effect of specific design changes, while holding other vehicle attributes fixed.

Finally, I have presented evidence that automakers planned to build more large light trucks in response to the footprint-based light truck CAFE standards. A single stringent fuel economy standard would eliminate this type of gaming, discourage the continued use of light trucks (with low fuel economy) as essentially substitutes for cars, and encourage greater use of lighter, smaller, and safer vehicles. Details of vehicle design can be improved through direct safety regulations. Improvements in safety regulations will have a greater effect on occupant safety than fuel economy standards that are structured to maintain, but in reality may increase, vehicle size. 


\section{References}

Kahane, C.J., 2003. Vehicle weight, fatality risk and crash compatibility of model year 1991-99 passenger cars and light trucks. NHTSA DOT HS 809 662. U.S. Department of Transportation, National Highway Traffic Safety Administration, Washington, D.C.

Kebschull, S.A., Kelly, J., Van Auken, R.M., Zellner, J.W., 2004. An Analysis of the Effects of SUV Weight and Length on SUV Crashworthiness and Compatibility Using Systems Modeling and Risk-Benefit Analysis. DRI-TR-04-04-2. Dynamic Research, Inc., Torrance, California. July.

Van Auken, R.M., Zellner, J.W., 2005. Supplemental results on the independent effects of curb weight, wheelbase, and track on fatality risk in 1985-1998 model year passenger cars and 19861997 model year LTVs. DRI-TR05-01. Dynamic Research, Inc., Torrance, California.

Wenzel, Tom, and Marc Ross, 2004a. "Comments on Vehicle weight, fatality risk and crash compatibility of model year 1991-99 passenger cars and light trucks, DOT HS 809-662," Comments submitted to National Highway Traffic Safety Administration Docket NHTSA-200316318, March 24. LBNL-55418.

Wenzel, Tom, and Marc Ross, 2004b. "Comments in response to Advanced notice of proposed rulemaking, Reforming the automobile fuel economy standards program, NHTSA docket NHTSA-2003-16128," Comments submitted to National Highway Traffic Safety Administration Docket NHTSA-2003-16128, April 29. LBNL-55419

Wenzel, Tom and Marc Ross, 2005. "Comments in response to Average Fuel Economy Standards for Light Trucks, NHTSA docket number NHTSA-2005-22223," Comments submitted to National Highway Traffic Safety Administration Docket NHTSA-2005-22223, November 18. LBNL-60759.

Wenzel, Tom and Marc Ross, 2008. "Comments in response to Advanced Notice of Proposed Rulemaking, Corporate Average Fuel Economy Standards for Passenger Cars and Light Trucks, Model Years 2011-2015, NHTSA docket number NHTSA-2008-0089," Comments submitted to National Highway Traffic Safety Administration Docket NHTSA-2008-0089, July 1.

Wenzel, Tom, 2009. Analysis of the Relationship Between Vehicle Weight/Size and Safety, and Implications for Federal Fuel Economy Regulation; Draft Report prepared for the Office of Energy Efficiency and Renewable Energy, US Department of Energy. August draft. 